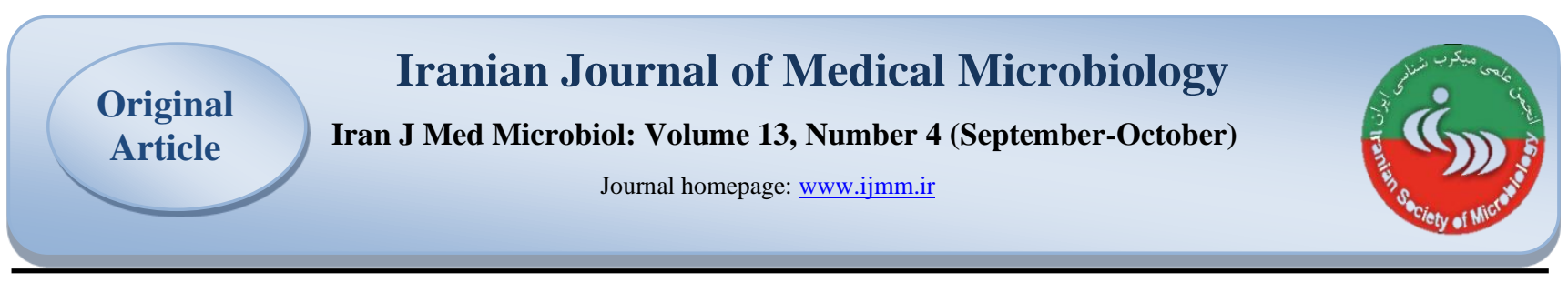

\title{
Visualizing the Clusters and Dynamics of HPV Research Area
}

\section{Farshid Danesh $^{1}$ (D), Somayeh GhaviDel ${ }^{2 *(D)}$}

1. Assistant Professor, Information Management Research Group, Regional Information Center for Science and Technology (RICeST), Shiraz, Iran

2. Ph.D. Student of knowledge and Information Science, Department of knowledge and Information Science, School of

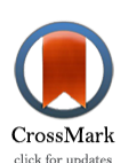
Psychology and Educational Sciences, Kharazmi University, Tehran, Iran

\section{Article Information}

\section{Article Subject: Virology}

\subsection{9/ijmm.13.4.266}

Corresponding author:

\section{Somayeh GhaviDel}

Department of knowledge and Information Science, School of Psychology and Educational Sciences, Kharazmi University, Tehran, Iran

Email:

s.ghavidel@tehranpl.ir

Use your device to scan and read the article online

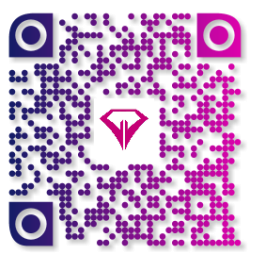

\begin{abstract}
Background and Aims: Co-word analysis, based on Co-occurrence, as one of the important techniques of Scientometrics and bibliometrics, enables the analysis of the content of scientific documents of the specific Research Area. The purpose of the present study is visualize HPV clusters relationships and thematic trends in the world.

Materials and Methods: The research type is an applied one with analytical approach and it has been done using co-word analysis. The population of this study consists of articles' keywords indexed during 2014-2018 in the Web of Science (WoS) in HPV subject area. The total numbers of the retrieved and analyzed keywords in this study were 13249. Some software like SPSS, UCINET and VOSViewer were used for data integration and analysis.

Results: The findings showed that the keyword "CERVICAL CANCER" have had the highest frequency and with "CERVICAL INTRAEPITHELIAL NEOPLASIA" and they were co-word couples. The results of the strategic diagram showed that the most clusters in HPV placed in third area of strategic diagram, it means these subjects (clusters) were emerging or declining.

Conclusion: Co-word analysis is suitable method for discover and visualize different sciences and their prominent patterns, hidden relationships and thematic trends research' subject areas. The results of these analysis and findings of such researches will help research policy makers
\end{abstract}

Keywords: Human Papilloma Virus, Papillomavirus, Co-occurrence, Co-Word Analysis, strategic diagram, UCINET, VOSviewer, HPV, bibliometrics, Scientometrics, Knowledge Structure, Visualizing

Received: 2019/11/25 Accepted: 2020/01/19 Available online: 2020/01/25

Copyright $\odot 2019$ Iranian Journal of Medical Microbiology. This is an open-access article distributed under the terms of the Creative Commons Attribution License (http://creativecommons.org/licenses/by/4.0), which permits unrestricted use, distribution, and reproduction in any medium, provided the original work is properly cited.

How to cite this article:

\section{Danesh F, Ghavidel S. Visualizing the Clusters and Dynamics of HPV Research Area. Iran J Med} Microbiol. 2019; 13 (4) :266-278

Download citation: BibTeX | RIS | EndNote | Medlars | ProCite | Reference Manager | RefWorks Send citation to: $8 \underline{\text { Mendeley }} \mathbf{Z} \underline{\text { Zotero }} \underline{\underline{\text { RefWorks }}}$ 


\section{Introduction}

HPV is the most common sexually transmitted infection (STIs) that causes cervical cancer, genital warts (1), and other human cancers such as genital, oral, head and neck, skin, anus, vagina, and penis cancers (2-4). As one of the most challenging fields, many HPV kinds of research were done, where the number of international scientific publications in this area is quantitatively remarkable. Incessant researches over time have led to the formation of the scientific structure of the HPV research area in medical sciences. Most of HPV's authoritative and essential articles are indexed in internationally accredited citation databases (Web of Science and Scopus), which are used in scientometrics studies and analyses.

The research method used for scientific mapping and science measurement studies is Coword analysis. This method studies the conceptual structure and evolution of a research field using document keywords and opens the possibility of revealing emerging clusters as well as developed clusters to predict research future for researchers $(5,6)$.

Given the importance of scientific papers as a suitable metric for measuring science progression, HPV results' analyses identify strengths and weaknesses in research areas related to that. They then discover the potentialities for research work to follow and use in support of that. This issue and ultimately, the path towards greater affection is the way-to-go for the planners, decision-makers, and policymakers at the Ministry of Health and
Medical Education and exclusively, for the scientific communities and the researchers. Therefore, given the strategic importance of this study and the fact that no research has been conducted so far, the necessity of doing so is deeply felt. Based on the theoretical framework explained before, the purpose of this study is to visualize the clusters and HPV dynamicity.

\section{Materials and Methods}

The present study is an applied one that was done using Co-word analysis, which is one of the scientific methods. This method illustrates HPV articles' thematic structure and content by calculating the number of occurrences and hidden connections between the words and concepts in HPV. To add to this, Data was collected from the Web of Science (WoS) Citation Database. The statistical population of this study includes all articles' keywords in the HPV subject area indexed in Web of Science (WoS) from 2014 to 2018. Worthy of mentioning, HPV specific keywords were extracted from Medical Subject Headings (MeSH).

Hierarchical clustering was performed using SPSS software (SPSS Inc., Chicago, III. USA). Visualization was also performed using VOSviewer software to show the high-frequency keyword structure. The threshold was set to 28 for analyzing the co-occurrence of 17278 keywords from 13249 articles.

\section{Results}

Table 1. Top 10 HPV Subject Area keywords' ranking based on co-word analysis (2014-2018)

\begin{tabular}{|clc|}
\hline No. & \multicolumn{1}{c}{ Keywords Title } & Frequency \\
\hline $\mathbf{1}$ & CERVICAL CANCER & 1919 \\
\hline $\mathbf{2}$ & HPV VACCINE & 772 \\
\hline $\mathbf{3}$ & HEAD AND NECK CANCER & 582 \\
\hline $\mathbf{4}$ & CERVICAL INTRAEPITHELIAL NEOPLASIA & 475 \\
\hline $\mathbf{5}$ & HPV VACCINATION & 434 \\
\hline $\mathbf{6}$ & SQUAMOUS CELL CARCINOMA & 362 \\
\hline $\mathbf{7}$ & HIV & 325 \\
\hline $\mathbf{8}$ & P16 & 289 \\
\hline $\mathbf{9}$ & OROPHARYNGEAL CANCER & 284 \\
\hline $\mathbf{1 0}$ & HEAD AND NECK SQUAMOUS CELL CARCINOMA & 239 \\
\hline
\end{tabular}


Table 2. Top 10 co-word pairs' Ranking in HPV Subject Area (2014-2018)

\begin{tabular}{|c|l|c|}
\hline No. & \multicolumn{1}{|c|}{$\begin{array}{c}\text { co-word pairs } \\
\text { Frequency }\end{array}$} \\
\hline 1 & CERVICAL CANCER ${ }^{*}$ CERVICAL INTRAEPITHELIAL NEOPLASIA & $\mathbf{1 5 3}$ \\
\hline 2 & HPV VACCINE** CERVICAL CANCER & $\mathbf{1 3 1}$ \\
\hline 3 & HPV VACCINATION** CERVICAL CANCER & $\mathbf{9 0}$ \\
\hline 4 & ADOLESCENT** HPV VACCINE & $\mathbf{8 3}$ \\
\hline 5 & HEAD AND NECK CANCER** OROPHARYNGEAL CANCER & $\mathbf{6 6}$ \\
\hline 6 & HIV** CERVICAL CANCER & $\mathbf{6 6}$ \\
\hline 7 & GENOTYPE** CERVICAL CANCER & $\mathbf{6 6}$ \\
\hline 8 & SQUAMOUS CELL CARCINOMA** HEAD AND NECK CANCER & $\mathbf{6 4}$ \\
\hline 9 & RADIATION THERAPY** HEAD AND NECK CANCER & $\mathbf{6 2}$ \\
\hline 10 & HPV16** CERVICAL CANCER & $\mathbf{5 5}$ \\
\hline
\end{tabular}

Table 3. Density and centrality of clusters derived from the co-word analysis in HPV subject area (2014-2018)

\begin{tabular}{|lcc|}
\hline \multicolumn{1}{c}{ Cluster name } & Centrality & Density \\
\hline 1. Tobacco and alcohol consumption & 0 & 16 \\
\hline 2. Targeted Therapy & 20.75 & 10.62 \\
\hline 3. Immune and biological systems & 2.4485 & 1.1765 \\
\hline 4. HPV Deaths & 10.5 & 13 \\
\hline 5. HPV Symptoms and Diseases & 1.133 & 0.3908 \\
\hline 6: HPV Diagnosis and Suppression Methods & 8.25 & 4.9556 \\
7. HPV Cancer & 7.3333 & 4.3571 \\
\hline 8. HPV Growth Cycle & 0 & 32 \\
\hline 9. Timely detection of HPV genotypes and cells & 33.0455 & 6.5385 \\
\hline 10. Cervical Cancer & 12.8 & 7.0667 \\
11.Sexual and communicable diseases & 20.6667 & 14.1 \\
\hline 12. Vaccination and prevention of genital warts & 8.6667 & 3.5091 \\
\hline 13. Safety and Security & 0 & 22 \\
\hline 14.Adolescent Immunization & 29.2 & 13.3333 \\
\hline Mean & 12227.83279 & 3962.891227 \\
\hline
\end{tabular}

Tablae 4. Clusters' names in quadrants of strategic diagram

\begin{tabular}{ll}
\multicolumn{1}{c}{ Clusters } & Quadrant \\
C 8. HPV Growth Cycle & Quadrant II \\
C 13. Safety and Security & Q 1. Tobacco and alcohol consumption \\
C 3. Immune and biological systems & Quadrant III \\
C 4. HPV Deaths & \\
C 5. HPV Symptoms and Diseases & C 6: HPV Diagnosis and Suppression Methods \\
C 7. HPV Cancer & Quadrant IV \\
C 10. Cervical Cancer & \\
C 12. Vaccination and prevention of genital warts & \\
C 2. Targeted Therapy & \\
C 9. Timely detection of HPV genotypes and cells & \\
C 11.Sexual and communicable diseases & \\
C 14.Adolescent Immunization &
\end{tabular}




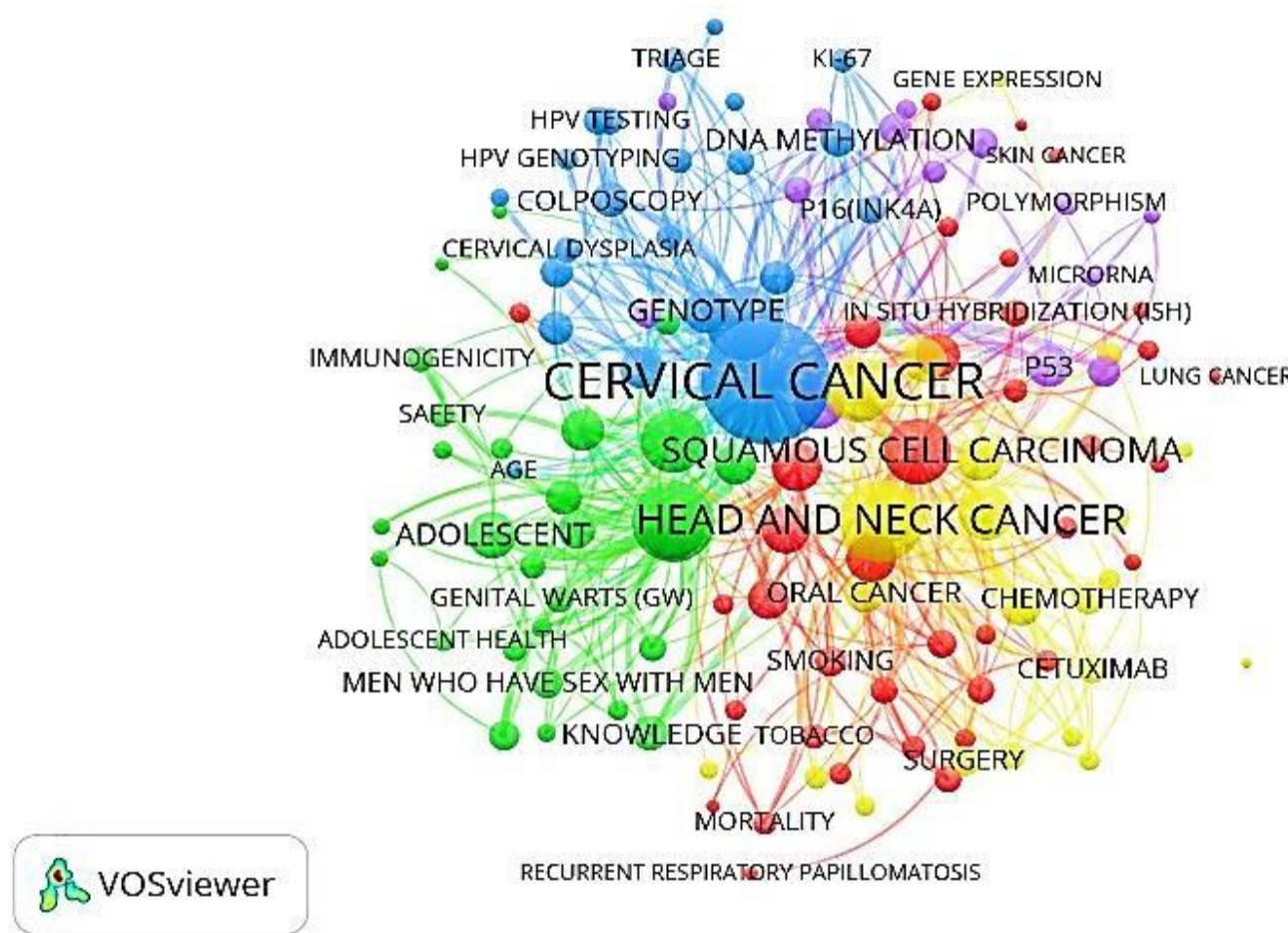

Figure 1. The network structure of high-frequency keywords in HPV subject area (2014-2018)

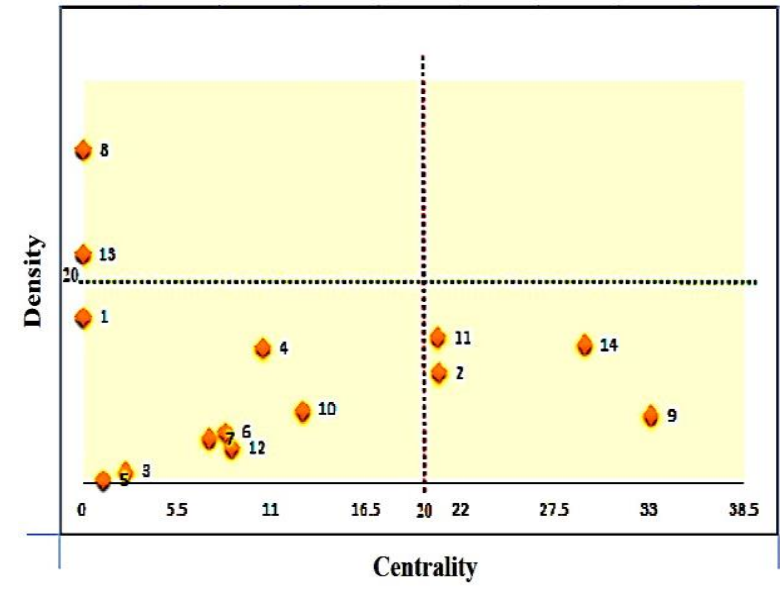

Figure 2. Strategic Diagram of HPV Subject Area Structure (2014-2018)

In Figure 1, the size of the nodes represents the weight of each author's scientific output, and the colors also represent the clusters formed.

A strategic diagram was designed to determine the maturity and development of clusters using concepts of centrality and density plotted on a twodimensional grid. The $x$-axis of the grid shows how strongly a cluster connected to others, and the $y$ axis shows a cluster's development.
Clusters of 8,13 , and 1 the highest density and clusters of 9,14 , and 2 , respectively, have the highest centrality (Figure 2). The origin of the strategic diagram is adjusted according to the mean centrality and density of the clusters.

\section{Discussion and Conclusion}

The present paper followed previous bibliometrics. So far, Research findings indicate that the most frequent keyword among HPV studies is "CERVICAL CANCER." Using a hierarchical clustering method to identify the intellectual structure of this subject area resulted in the formation of 14 subject clusters (Table 3 ). The plotting results of the distribution of clusters in the strategic diagram (Figure 2) indicated that the thematic areas of "HPVinduced cancers," "vaccination," "prevention", and "genital warts" are the most important emerging areas in this subject area. Last but not least are the subject areas of drug, cancer treatment, timely diagnosis, sexually transmitted diseases, and immunization of adolescent health, which expect further research in the future. 
Clusters located in the second region of the strategic diagram (Figure 2) are not axial but considered developed. The third region clusters have lower centrality and density than the other clusters, so they are marginal, and at the same time, emerging and declining. The fourth region clusters present a strategic diagram that is pivotal but general and broad.

Co-word analysis is an appropriate way of discovering and mapping science, knowledge tracking, visualization, conceptual dynamics, and transformation, identifying and analyzing research fields in the subject areas by researchers that help planners and policymakers.

In the end, we suggested that another research be done in Persian scientific journals (Persian articles) with the focus of the HPV research area (using Co-word Analysis) so that the results will compare with the ones obtained in this study. Finally, researchers also suggested that in another study, all HPV publications in this subject area through the world and from the first article publication so far, do with co-occurrence analysis and the results are available to medical policymakers in the country and other international health organizations.

\section{Acknowledgements}

The researchers appreciate reviewers for their valuable comments.

\section{Conflict of Interest}

This article is the result of an independent study conducted without organizational financial support. In the present study, the authors showed no conflict of interest. 


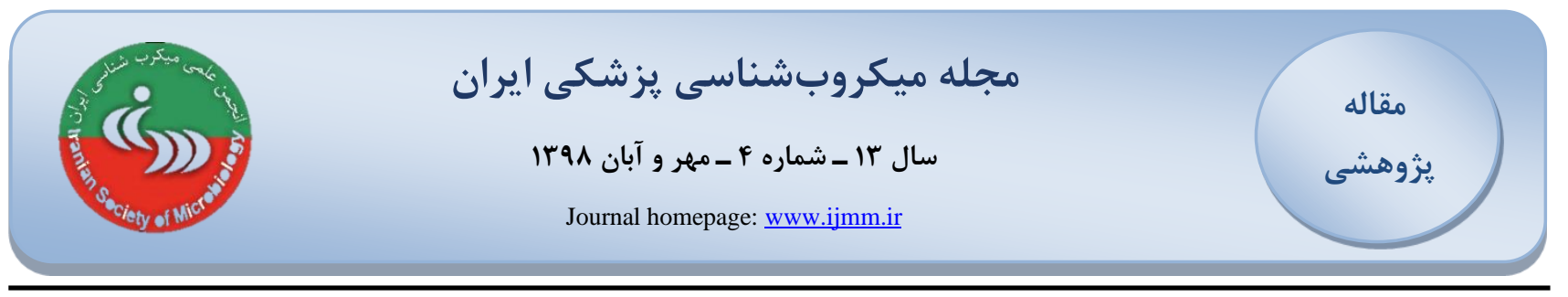

\section{HPV ديدارىسازى خوشهها و يويايى قلمروى موضوعى}

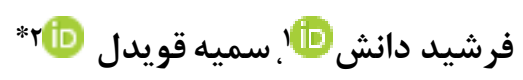

l.

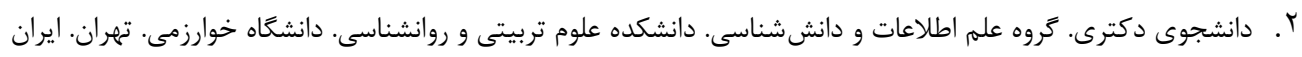

\begin{tabular}{|c|c|}
\hline جـكبـه & اطلاعات مقاله \\
\hline زمينه و اهدف: تحليل هموازًّانى، براساس همرخدادى وازًّان، بهعنوان يكى از تكنيكهاى مهم علهمنجى و كتابسنجى، & تاريخجة مقاله \\
\hline 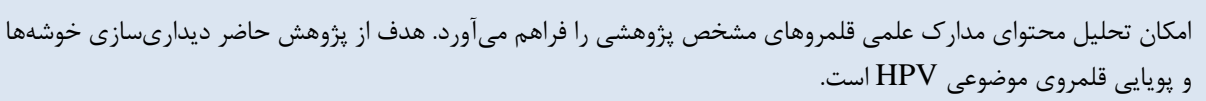 & 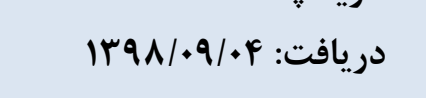 \\
\hline مواد و روش كار : يزوهش حاضر از نوع كاربردى است كه با روش تحليل همرخدادى وازگًان كه از روشهاى علمسنجى & 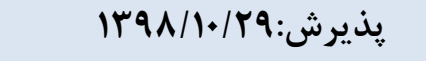 \\
\hline است با رويكرد تحليلى انجام شده است. كليدوازههاى مقالات نمايهشده در وبكاه علم در قلمروى موضوعى HPV بين سالهاى & 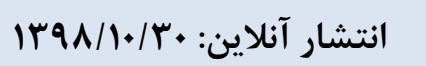 \\
\hline 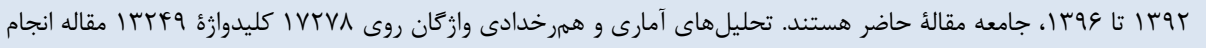 & \\
\hline كرديد. بِ از انجام فرآيند يكدستسازى وارَّان، نقطه برش مشخص و براى تحليل و آمادهسازى دادهר ها و نيز ترسيم نقشهها، & 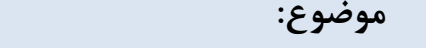 \\
\hline از نرمافزارهاى يو.سى.آى.نت(UCINET)، VOSviewer (نسخه & 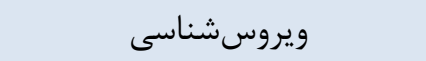 \\
\hline يافتهها: كليدوازٔه ״CERVICAL CANCER هاراى بيشترين فراوانى و با CERVICAL INTRAEPITHELIAL NEOPLASIA & IJMM1398;13(4): 266-278 \\
\hline زوج هموازًانى است. بيشتر مطالعات HPV در ناحئ ب نمودار راهبردى يعنى موضوعات نويديد و يا روبلزوال قرار دارد. & نويسندهُ مسئول: \\
\hline نتيجهكيرى: تحليل همرخدادى واركًان، ابزار مناسب و قدرتمندى است كه در كشف و ديدارىسازى علم و دانش، رديابى علوم، سير & كروه علم اطلاعات و \\
\hline يويايى مفهومى و تعيين و تحليل نواحى مورد يُوهش در قلمروهاى موضوعى كمك بسيارى به برنامهريزان و سياست كذاران يروهشى مى كند. & دانششناسى. دانشكده علوم تربيتى و \\
\hline كليد وازهها: كتابشناسى، علمسنجى، همرخدادى واثَّان، تحليل هموازَّانى، ويروس پإييلوم انسانى، نمودار استراتزيك، & روانشناسى. دانشكاه خوارزمى. تهران. ايران \\
\hline ديدارىسازى & ايميل: S.ghavidel@tehranpl.ir \\
\hline
\end{tabular}

مقدمه

يثروهشى HPV در علوم يزشكى شده اند. اغلب مقالههاى معتبر و مهم قلمروى موضوعى HPV در پيايخاههاى استنادى نمايه شدهاند كه در مطالعات و تجزيهوتحليلهاى علمسنجى استفاده مىشوند. يكى از روشهاى ترسيهم نقشههاى علمى و مطالعات سنجش

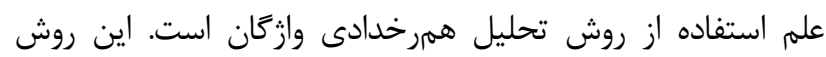
ساختار مفهومى و تكامل يك قلمرو يثوهشى را با استفاده از كليدوازههاى مدارك، مطالعه مى كند و امكان آشكارسازى خوشههاى

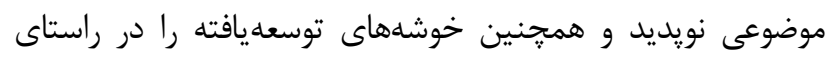

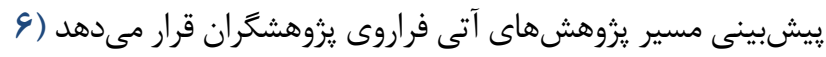

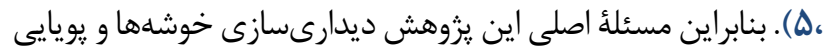
قلمروى موضوعى HPV است. درنهايت با توجه به اهميت مقالات علمى بهعنوان سنجهاى

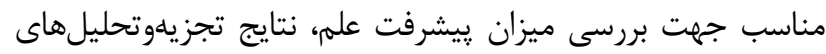

HPV شايع ترين عفونت مقاربتى شناختهشدهاى است كه عامل سرطان دهانٔ رحم و زگيل دستخاه تناسلى است (1). سرطان دهانٔ رحم نيز يكى از علل مرگومير ناشى از سرطان در كشورهاى

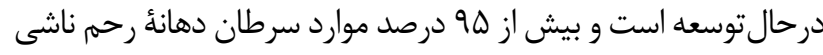

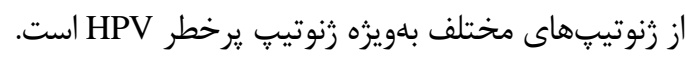

تاكنون بيش از • ال ز زنوتيب Papillomavirus انسانى(HPV) كشف شده است كه در بروز ديخر سرطانهاى انسانى شامل،

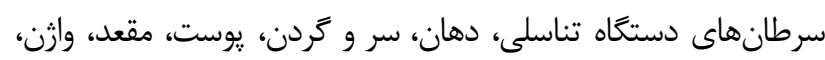
آلت تناسلى مردان (Y-Y) هم دخيل هستند. مطالعات عفونتهاى نشانگر اين واقعيت نيز هستند كه اكثريتِ قريب مبهاتفاق بانوان جوان درگير عفونتهاى ويروس مذكور هستند (1). به همين دليل، در قلمروى موضوعى HPV، يزوهشهاى زيادى انجام شده و كمّيت توليدات علمى در سطح بينالمللى قابلتوجه است؛ يزوهشهاى

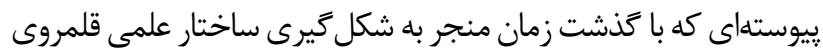


مطالعات علمسنجى روزآمد و جامع، ضرورت اجراى اين يزوهش را

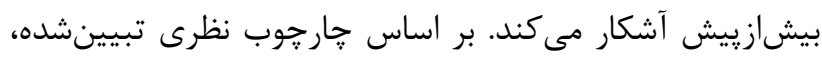

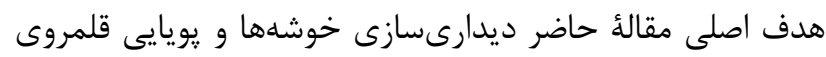

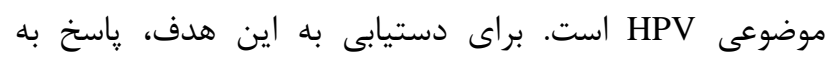

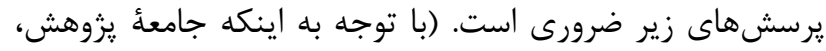

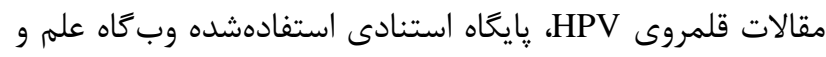

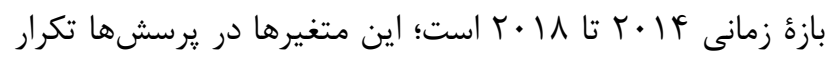

$$
\text { نمىشود). }
$$

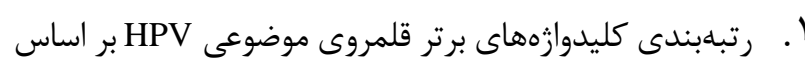

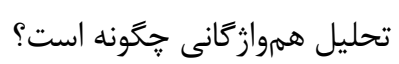

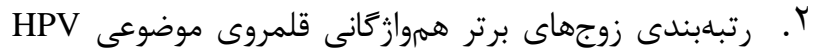

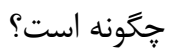

r. تراكم و مركزيت خوشههاى حاصل از تحليل هموازكانى

$$
\text { قلمروى موضوعى HPV جگَّنه است؟ }
$$

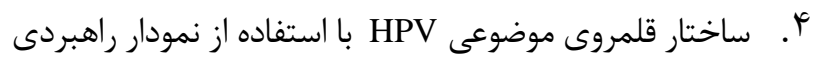

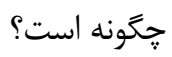

\section{مواد و روش كار}

يزوهش حاضر از نوع كاربردى است كه با روش تحليل

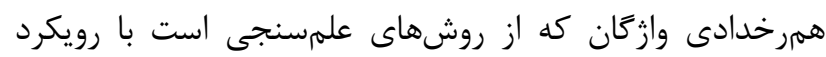

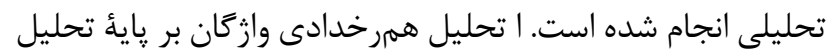

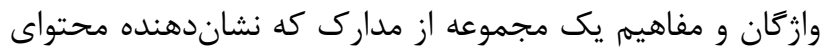

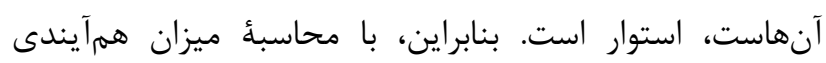

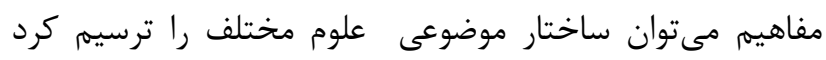

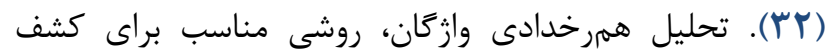

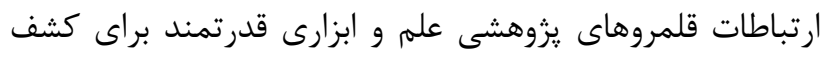

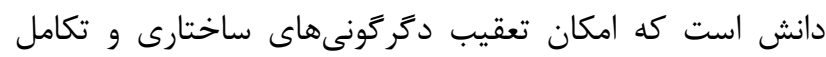

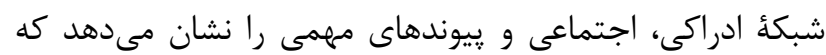

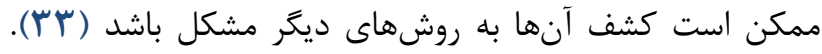

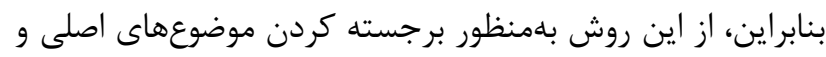

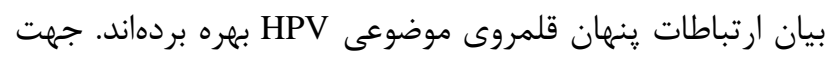

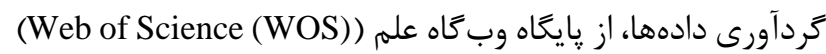
كه معتبرترين و قديمىترين پايگاه استنادى است، استفاده شد.

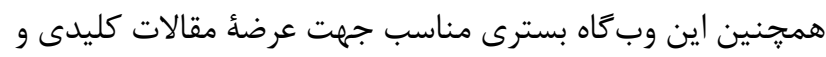

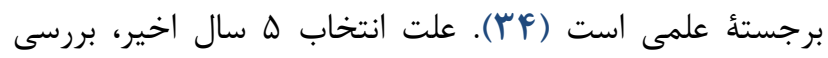

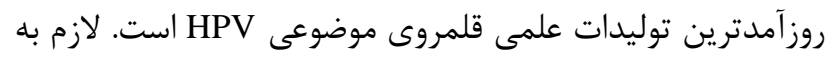
ذكر است، كليدوازههاى تخصصى HPV از سرعنوانهاى موضوعى

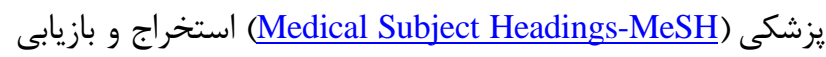

صورت گرفته در قلمروى HPV به شناسايى حوزههاى قوى و ضعيف يرزوهشى و كشف يتانسيل لازم در كارهاى يزوهشى منتج خواهد شد.

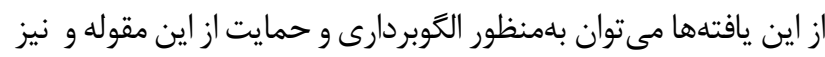

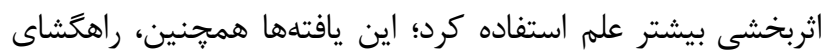

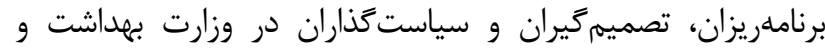

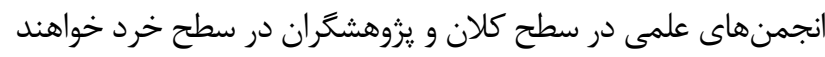

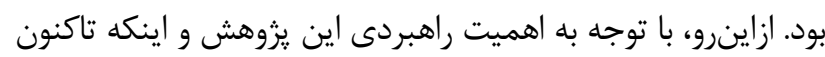

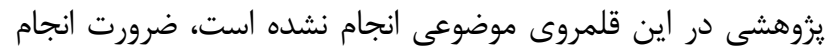
اين يزوهش بيش از بيش احساس كرديد. در ادامه اين مقاله يِيشينهاى مهرم و مرتبط درخصوص تحليلهاى هموازًَانى با رويكردى تحليلى مرور مىشود. با توجه دئه

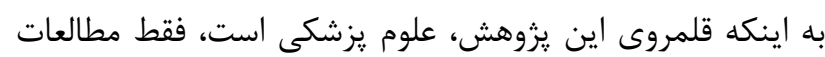

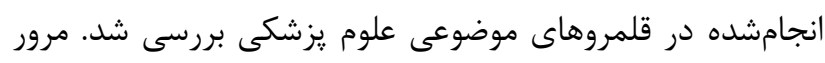

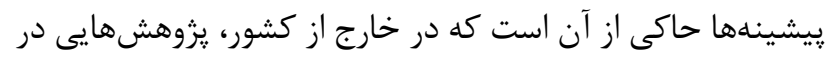

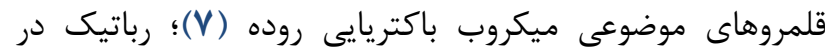

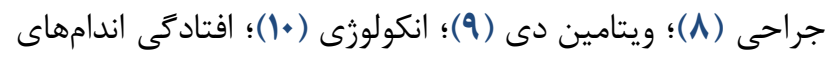

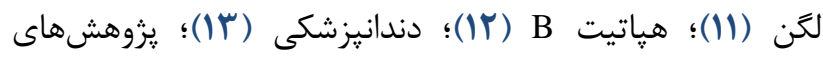

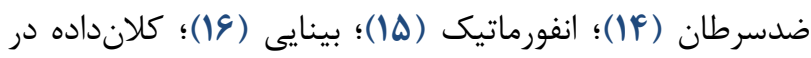

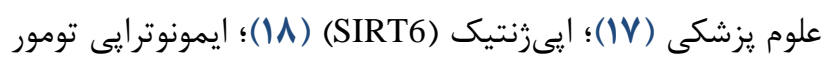

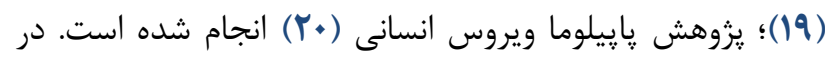

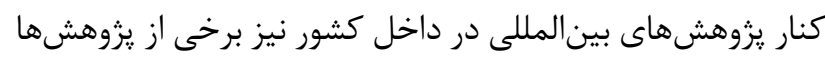
مانند ميكروبشناسى (Iا)؛ تجهيزات يزشكى و آزمايشكاهى (9)؛

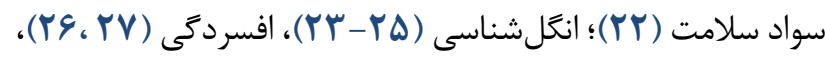

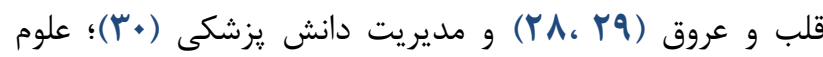

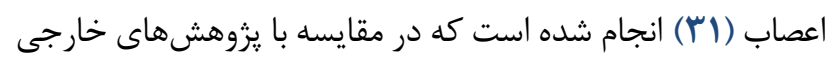
از نظر تعداد بسيار اندى است.

بررسى ييشينههاى يزوهش حاكى از آن است كه تحليل

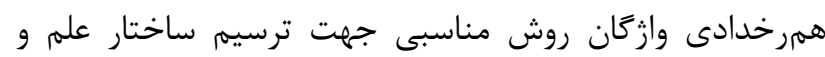

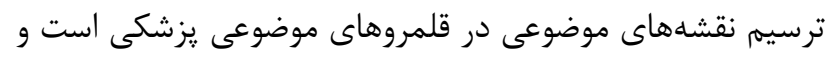

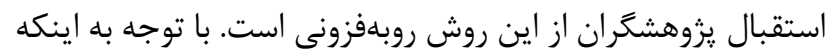

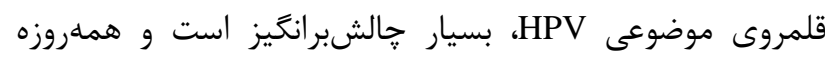

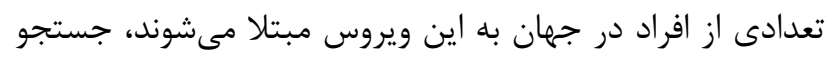

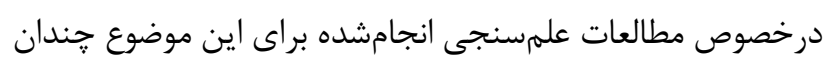

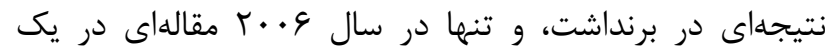

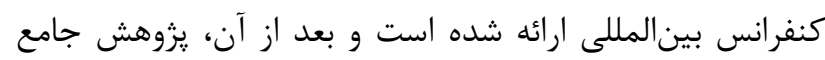

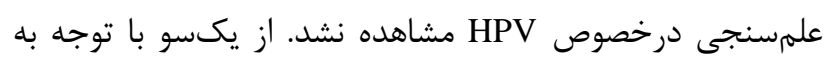
وسيع بودن انتشارات اين حوزه يزوهشى و از سوى ديكر انجامنشدن 


\section{نتايج}

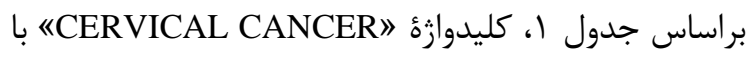

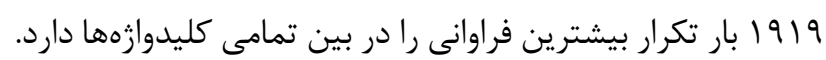

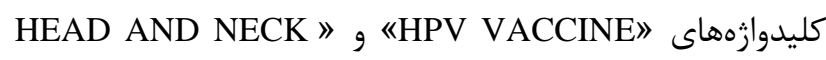

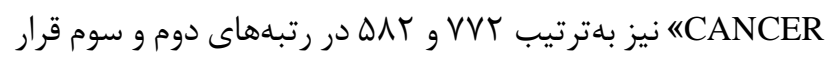
كرفتهاند.

شكل I كليدوازمهاى :ربسامد يزوهشهاى HPV را نشان

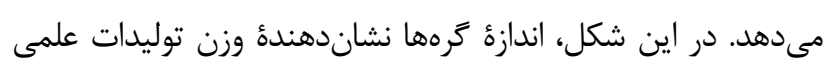

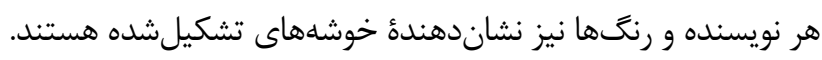

\section{HPV رتبهبندى •ا زوج برتر هموازَّانى قلمروى موضوعى}

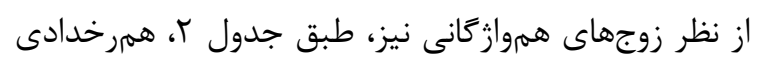

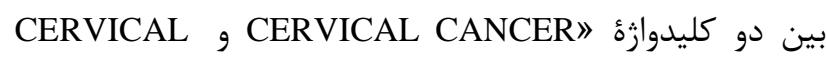
«INTRAEPITHELIAL NEOPLASIA بيشترين فراوانى تكرار و بسامد وازكانى را در يزوهشهاى قلمرو HPV داشتهاند و دو زوج HPV و و "CERVICAL CANCER, HPV VACCINE» "CERVICAL CANCER , VACCINATION و سوم قرار دارند. بانظر مىرسد بيشترين يزوهشها در هر بازه

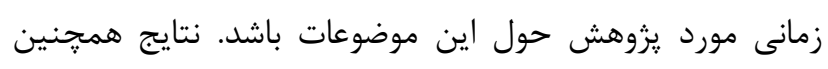

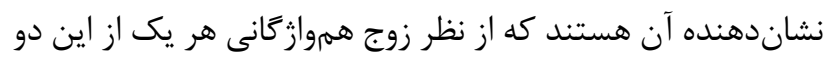

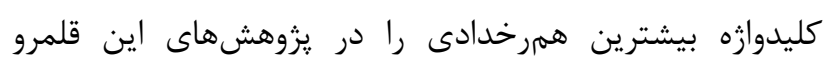
داشتهاند كه نشاندهنده قرابت زياد اين مباحث با يكديخر است.
شدند. يس از يافتن كليدوازهها، اين كليدوازهها در بخش جستجوى

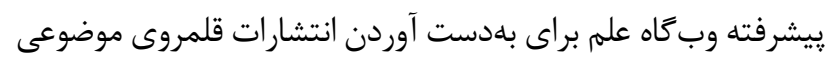

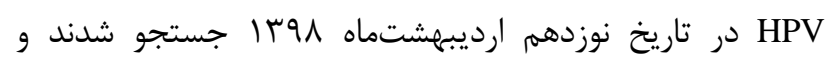

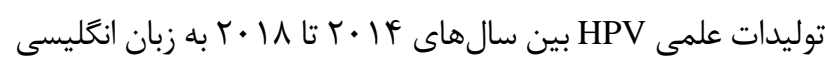
بازيابى و براى تحليلهاى بعدى ذخيره كرديد. با استفاده از نرمافزار سارئ (SPSS Inc., Chicago, Ill., USA SPSS 16

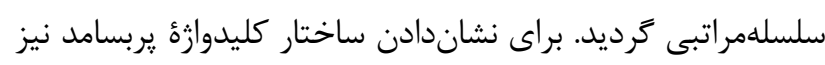
با استفاده از نرمافزار VOSviewer (نسخه

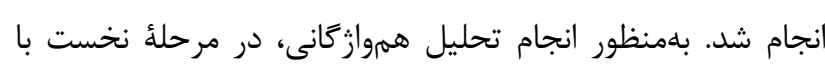

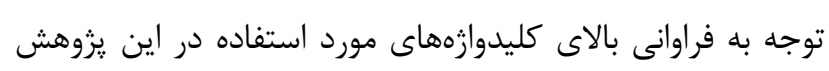

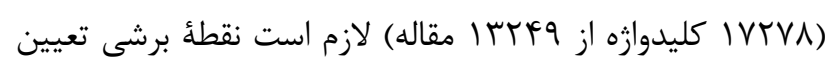

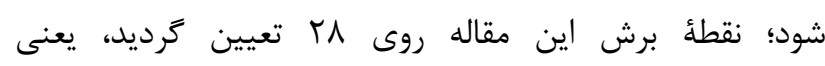

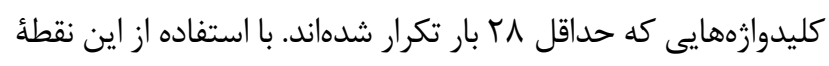

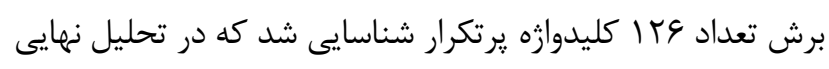

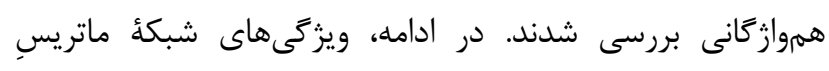

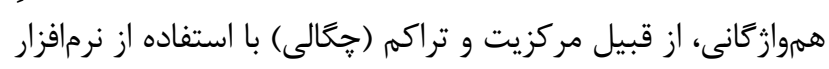

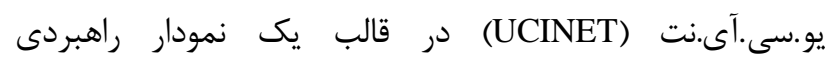

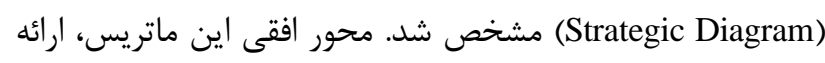

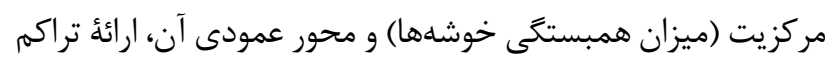

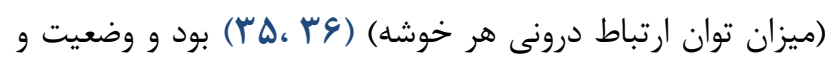
كرايشهاى تكاملى قلمروى موضوعى HPV آشكار شد.

\& VOSviewer

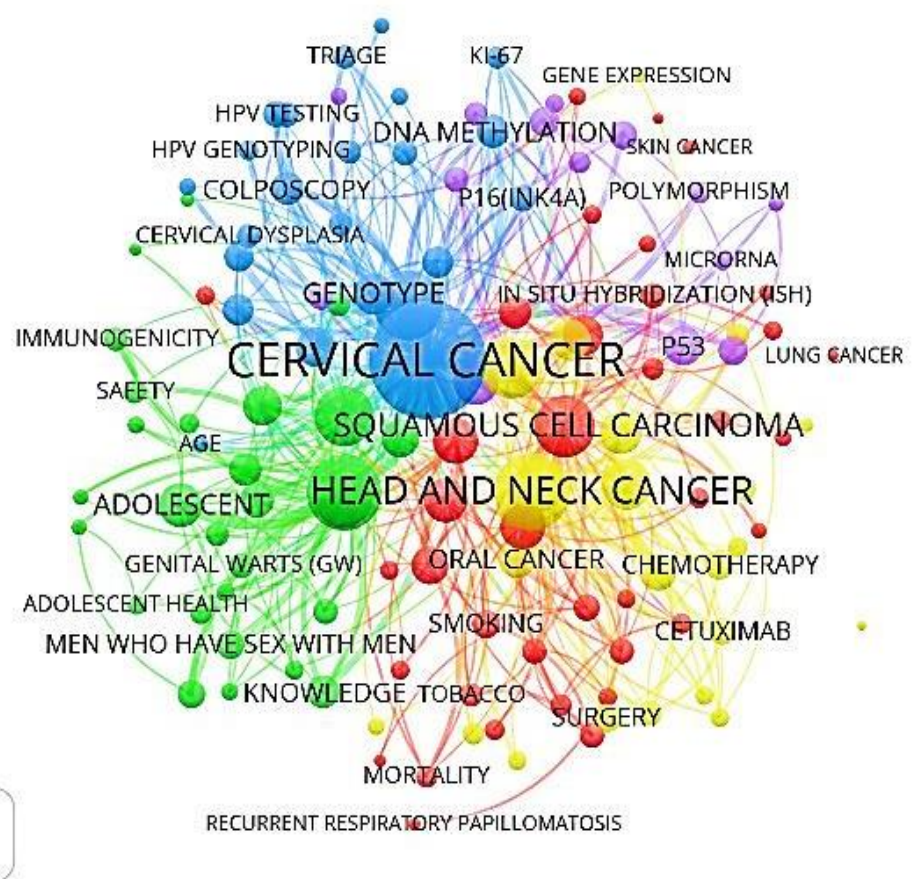

شكل ا. ساختار شبكأ كليدوازههاى يربسامد قلمروى موضوعى HPV 
جدول ا. رتبهبندى • ا كليدوازٔه برتر قلمرو HPV

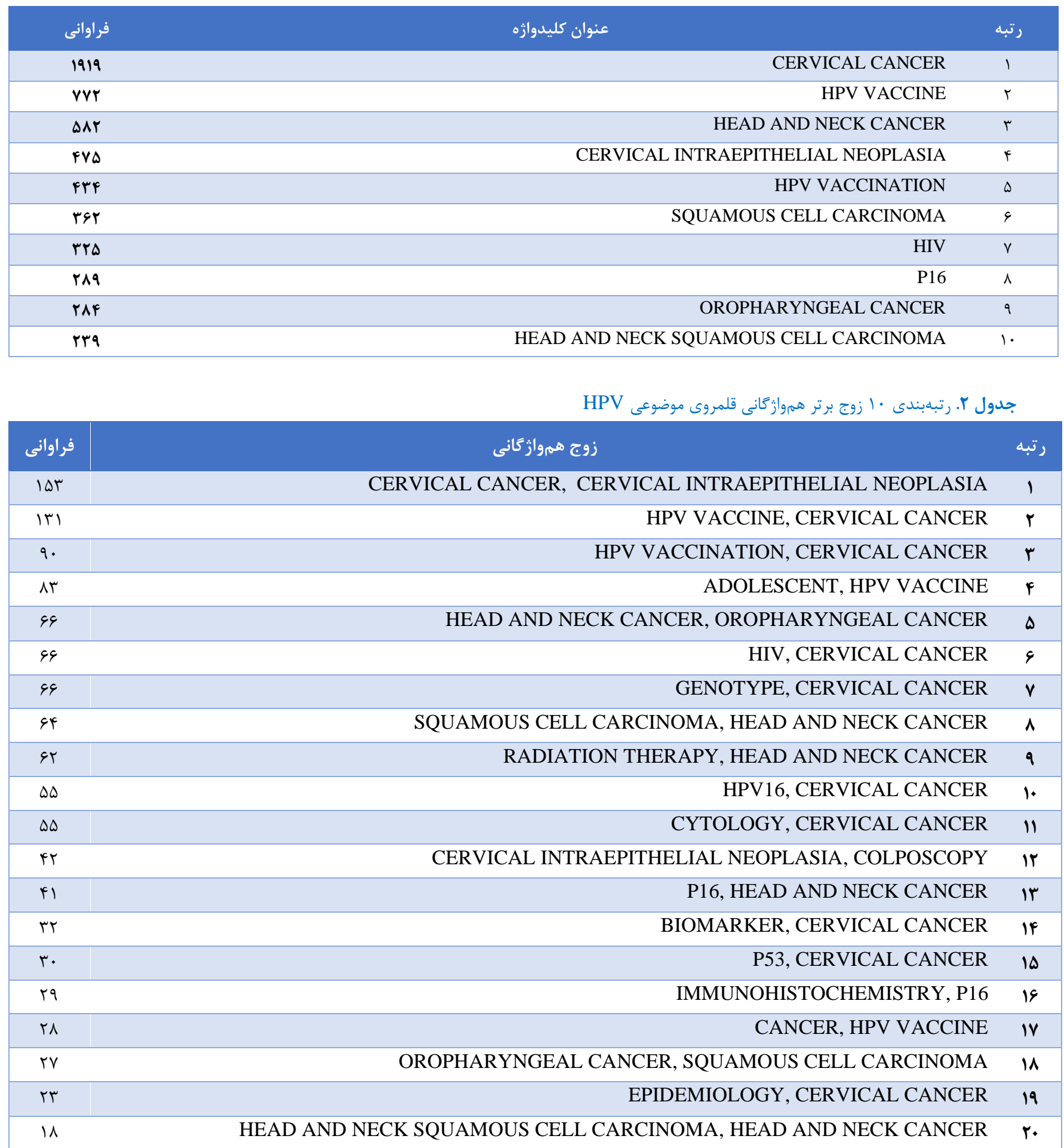

جدول rا. تراكم و مركزيت خوشههاى حاصل از تحليل هموازَكانى قلمروى موضوعى HPV

\begin{tabular}{|c|c|c|}
\hline تراكم & مركزيت & نام خوشه \\
\hline 18 & $\cdot$ & 1: مصرف دخانيات و الكل \\
\hline 1.194 & $r \cdot / V \Delta$ & ז: دارودرمانى سرطان \\
\hline $1 / 1 \vee 9 \Delta$ & T/FYAD & "ז: سيستم ايمنى و بيولوزيكى \\
\hline ir & $1 \cdot / 0$ & FPV مرك ناشى از HPV \\
\hline
\end{tabular}




\begin{tabular}{|c|c|c|}
\hline$\cdot / r q \cdot \wedge$ & 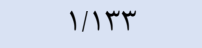 & هPV علائم و بيمارىهاى HPV \\
\hline$F / 9 \Delta \Delta q$ & $\Lambda / r \Delta$ & צ: روشهاى تشخيص و سركوب HPV \\
\hline$r / r \Delta v i$ & V/TrTr & 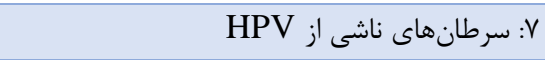 \\
\hline re & · & A: جرخهُ رشد و تكثير HPV \\
\hline 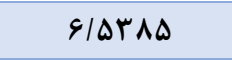 & $r r / \cdot F \Delta \Delta$ & 9: تشخيص بهنگام رنو تيبها و ياختههاى HPV \\
\hline$V / .99 V$ & $\mid r / \Lambda$ & • ا: سرطان دهانهٔ رحمم . \\
\hline$|F /|$ & $r \cdot 1999 \mathrm{~V}$ & || إ: بيمارىهاى جنسى و مسرى \\
\hline$r / \Delta \cdot 9)$ & $1 / 999 \mathrm{~V}$ & rا: واكسيناسيون و ييشَيرى از زَيلهاى تناسلى \\
\hline tr & . & rا إيمنى و مصونيت \\
\hline 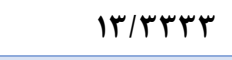 & $r q / 4$ & f ا ايمنسازى نوجوانان \\
\hline 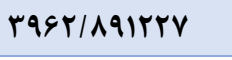 & ITtTVINTtVI & 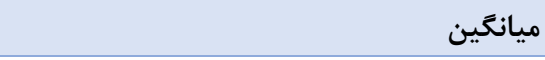 \\
\hline
\end{tabular}

محورى نبوده اما توسعهيافته قلمداد مىشوند. خوشههاى ا (مصرف

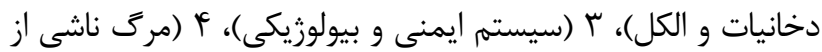

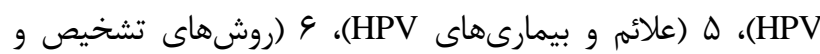
سركوب HPV)، V (سرطانهاى ناشى از HPV)، • (1 (سرطان دهانئ رحم) و Tا (واكسيناسيون و بيشخيرى از زخيلهاى تناسلى) در ناحئ سوم نمودار راهبردى جاى گرفتهاند. خوشههاى ناحيه سوم از مركزيت و تراكم يايينى نسبت به ساير خوشهها برخوردارند بنابراين حاشيهاى

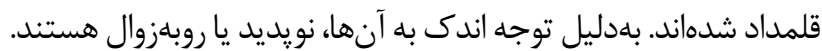
درنهايت، خوشههاى Y (دارودرمانى سرطان)، 9 (تشخيص بهنغام زنو لونه

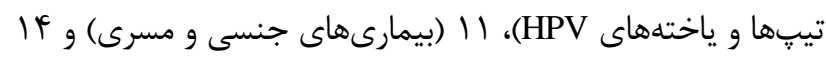
(ايمنسازى نوجوانان) در ناحيه جهارم نمودار راهبردى حضور دارند كه محورى بوده اما توسعهنيافته و نابالغ هستند.

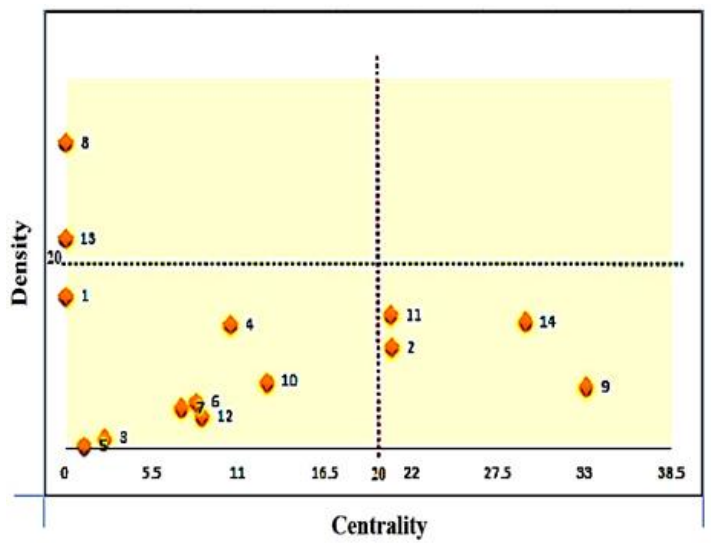

شكل r. نمودار راهبردى قلمروى موضوعى HPV

خوشههاى حاصل از تحليل هموازگًانى ازنظر بلوغ و توسعه يافتخى قلمروى موضوعى HPV

همانطور كه ييشتر نيز بيان شد خوشههاى داراى موضوعات

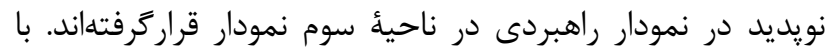

تراكم و مركزيت خوشههاى حاصل از تحليل هموازگًانى

قلمروى موضوعى HPV جهت تعيين بلوغ و توسعهيافتگى حاصل از تحليل هموازكانى با استفاده از مفاهيم مركزيت و تراكم شبكه، نمودار راهبردى طراحى تعائ

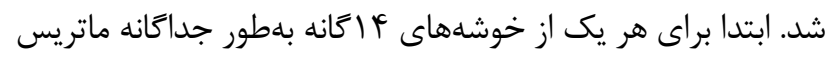

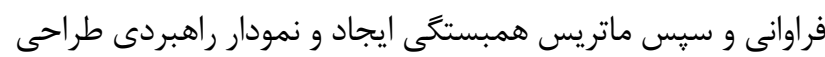

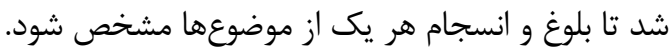

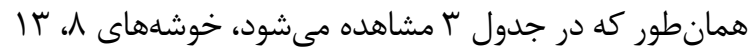
و ا به ترتيب بيشترين تراكم و خوشههاى 9، أl و و ب به ترتيب بالاترين مركزيت را دارند. نمودار راهبردى مربوط به خوشههاى

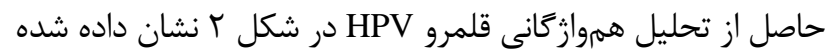
است. مبدأ نمودار با توجه به ميانكين مركزيت و تراكم خوشهها تنظيم شده است. قدرت تعامل هر يك از خوشهها در قلمرو مورد مطالعه در محور افقى و با مركزيت مشخص شده است. هر خه جه

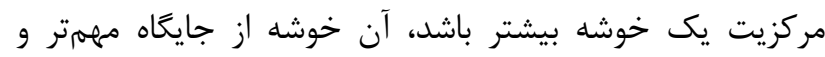
مركزىترى برخوردار است. رابطؤ درونى خوشههاى مورد مطالعه با بال

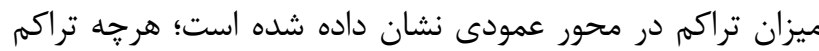

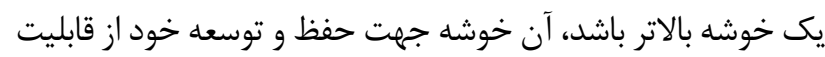

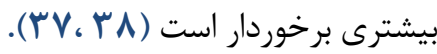

ساختار قلمروى موضوعى HPV با استفاده از نمودار راهبردى توزيع خوشهها در نمودار راهبردى (شكل r) اين يزوهش حاكى از آن است كه هيجيك از خوشهها در ناحيئ نخست قرار

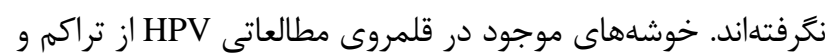
مركزيت بالايى جهت قراركيرى در اين قسمت برخوردار نبودهاند و

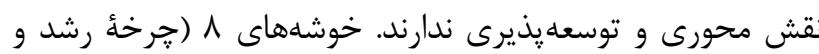

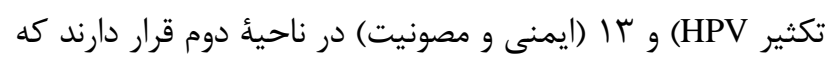


بيشترين فراوانى را در بين يزوهشهاى HPV، كليدوازه اسرطان

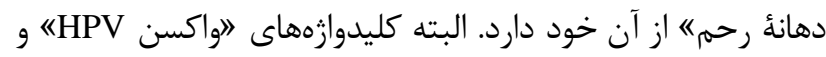

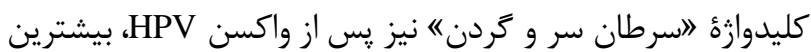

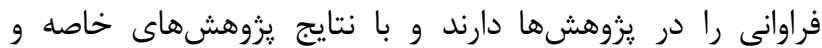

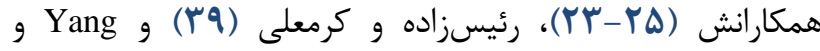

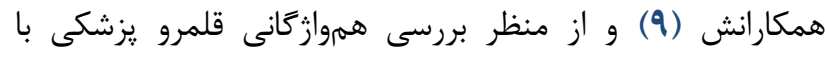

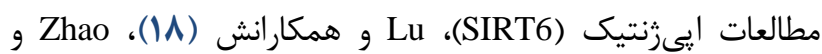

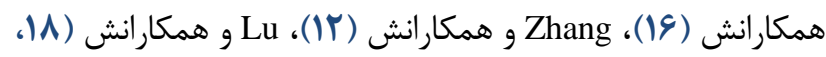

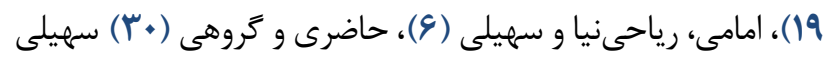

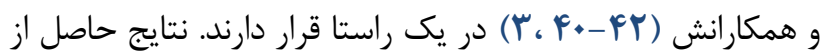
اين يزوهش سبب تقويت و مديريت بهتر يزوهشهاى اين قلمروى

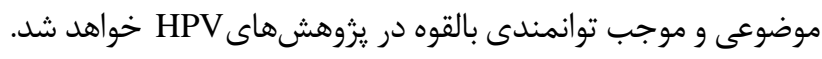

$$
\text { نتيجه كيرى }
$$

تحليل همرخدادى وازًان، روشى مناسب در كشف و ترسيم

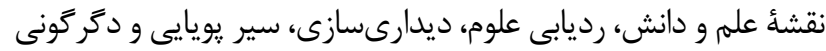

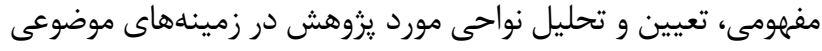

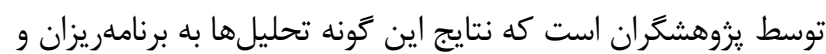
سياست كذاران يزوهشى كمك شايانى مى كند.

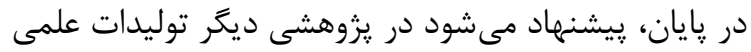

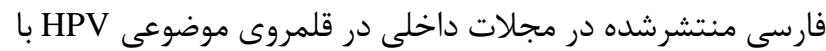
روش همرخدادى وازگًان تحليل و نتايج حاصل با نتايج به دست

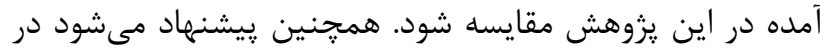

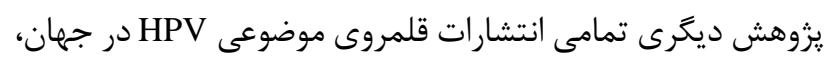
از انتشار نخستين مقاله تاكنون، با روش تحليل هموازكانى انجام

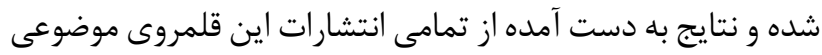
در اختيار سياست كذاران علوم يزشكى كشور قرار كيرد.

$$
\text { تشكر و قدردانى }
$$

بدينوسيله، بيشاييش از داوران محترم بهدليل ارائه نظرات

$$
\text { ارزشمند تشكر و قدردانى بهعمل مى آيد. }
$$

\section{Referance}

1. Braaten KP, Laufer MR. Human Papillomavirus (HPV), HPV-Related Disease, and the HPV Vaccine. Reviews in obstetrics \& gynaecology(Rev Obstet Gynecol), 2008; 1(1): 2-10.
نخاهى به شكل r كه نمودار راهبردى قلمروى موضوعى HPV است، شاهد خوشههاى I (مصرف دخانيات و الكل)، ب (دارودرمانى

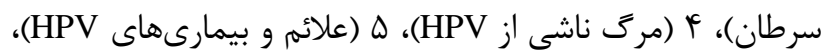
צ (روشهاى تشخيص و سركوب HPV)، V (سرطانهاى ناشى از

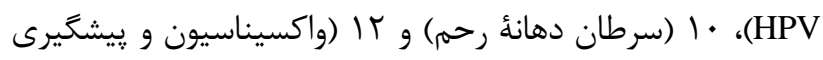

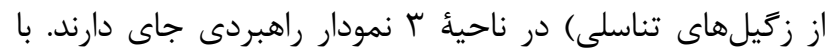
استفاده از شكل r مى توان موضوعات نويديد را بيخيرى نمود.

\section{بحث}

مدلها و نقشههاى علمى روش مناسبى براى نمايش رشد

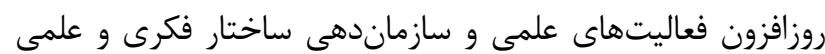
تشكيل دهندة يك قلمروى موضوعى است. در اين مقاله با استفاده از روش تحليل همرخدادى وازًان و با بهكاركيرى خوشهبندى استى

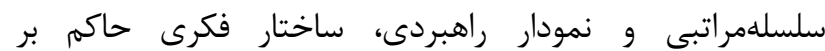
يزوهشهاى قلمروى موضوعى HPV در ه سال منتهى به سال

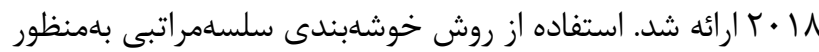

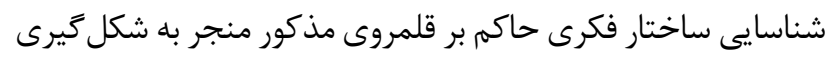
fl

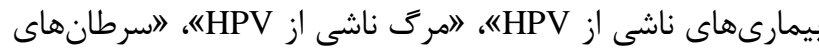

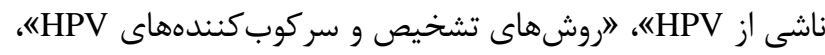
"(بيمارىهاى جنسى و مسرى"، الايمنى و واكسيناسيون و زنان و و نوجوانان" به جشم مى جورد.

نتايج حاصل از ترسيم نمودار راهبردى بيانكر آن است كه

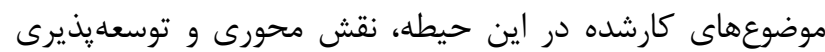

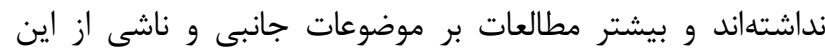

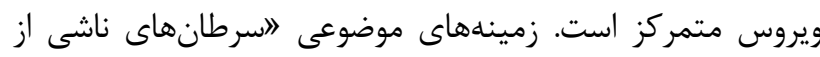
WPV مهرمترين زمينههاى نويديد اين قلمروى موضوعى هستند و البته در موضوعهاى دارو و درمان سرطان و تشخيص بهنغام، راهها و و بيمارىهاى مسرى آميزشى، ايمنسازى سلامت نوجوانان انتظار دران مىرود يزوهشهاى بيشترى در آينده انجام كيرد.

اين يزوهش در امتداد مطالعه كتابسنجى (•r) در بررسى مطالعات HPV بوده است. يافتههاى يزوهش حاكى از آن است كه

2. Khodakarami N, Hosseini S, Yavari $\mathrm{P}$, Farzaneh $\mathrm{F}$, Etemad K, Salehpour S, et al. Human papillomavirus infection prevalence in women referred to health clinic of Shahid Beheshti University of Medical Sciences, Tehran, 
Iran.Iranian Journal of Epidemiology(IJE), 2012; 7(4):3542. [In Persian]

3. Mobini Kesheh, M., Keyvani, H. The Prevalence of HPV Genotypes in Iranian Population: An Update. Iranian Journal of Pathology (Iran J Pathol), 2019; 14(3): 197-205. [DOI:10.30699/IJP.2019.90356.1861] [PMID] [PMCID]

4. Fakhraei F, Haghshenas MR. Human Papillomaviruses and Cancer. Journal of Mazandaran University of Medical Sciences)J Mazandaran Univ Med Sci(. 2013; 22(98):340-60. [In Persian]

5. Hu J, Zhang Y. Research patterns and trends of Recommendation System in China using co-word analysis. Information Processing \& Management. 2015; 51(4):329-39. [DOI:10.1016/j.ipm.2015.02.002]

6. Emami M, Riahinia N, Soheili F. Mapping the Scientific Structure of Medical and Laboratory Equipment Patents in USPTO database between 1984 and 2014. Journal of Payavarde Salamat. 2019; 12(6):419-32. [In Persian]

7. Hakim JA, Schram JB, Galloway A, Morrow CD, Crowley, MR, Watts SA, et al. The Purple Sea Urchin Strongylocentrotus purpuratus demonstrates a Compartmentalization of Gut Bacterial Microbiota, Predictive Functional Attributes, and Taxonomic CoOccurrence. Microorganisms. 2019; 7(2):35. doi: 10.3390/microorganisms7020035 [DOI:10.3390/microo rganisms7020035] [PMID] [PMCID]

8. Shen L, Wang S, Dai W, Zhang Z. Detecting the Interdisciplinary Nature and Topic Hotspots of Robotics in Surgery: Social Network Analysis and Bibliometric Study. Journal of Medical Internet Research(J Med Internet Res), 2019; 21(3):e12625. [DOI:10.2196/12625] [PMID] [PMCID]

9. Yang A, Lv Q, Chen F, Wang D, Liu Y, Shi W. Identification of Recent Trends in Research on Vitamin D: A Quantitative and Co-Word Analysis. Medical Science Monitor: International Medical Journal of Experimental and Clinical Research(Med Sci Monit), 2019; 25:643-55. [DOI:10.12659/MSM.913026] [PMID] [PMCID]

10. Moral-Munoz JA, Carballo-Costa L, Herrera-Viedma E, Cobo MJ. Production trends, collaboration, and main topics of the integrative and complementary oncology research area: a bibliometric analysis. Integrative Cancer Therapies(ICT), 2019; 18:1534735419846401. [DOI:10.1177/1534735419846401] [PMID] [PMCID]

11. Huang F, Zhou Q, Leng BJ, Mao QL, Zheng LM, Zuo MZ. A bibliometric and social network analysis of pelvic organ prolapse during 2007-2016. Journal of the Chinese Medical Association(JCMA), 2017; 81(5):450-7. [DOI:10.1016/i.jcma.2017.08.012] [PMID]

12. Zhang W, Wang YB, Zhang XZ, Duan HM. The study of hot spots on hepatitis $b$ dissertation based on co-word analysis in China. Studies in health technology and informatics(HTI), 2017; 245:1293.
13. Tarazona B, Vidal-Infer A, Tarazona-Alvarez $\mathrm{P}$, AlonsoArroyo A. Analysis of scientific production in Spanish implantology. Journal of clinical and experimental dentistry(SECIB), 2017; 9(5):e703-e11. [DOI:10.4317/jced.53718] [PMID] [PMCID]

14. Xie P. Study of international anticancer research trends via co-word and document co-citation visualization analysis. Scientometrics. 2015; 105(1): 611-22. [DOI:10.1007/s11192-015-1689-0]

15. Yao Q, Lyu P, Ma F, Yao L, Zhang S. Global informetric perspective studies on translational medical research. BMC Medical Informatics and Decision Making. 2013; 13:77. [DOI:10.1186/1472-6947-13-77] [PMID] [PMCID]

16. Zhao F, Shi B, Liu R, Zhou W, Shi D, Zhang J. Theme trends and knowledge structure on choroidal neovascularization: a quantitative and co-word analysis. BMC Ophthalmology. 2018; 18:2-11. [DOI:10.1186/s12886-018-0752-z] [PMID] [PMCID]

17. Zhang T, Chi H, Ouyang Z. Detecting research focus and research fronts in the medical big data field using co-word and co-citation analysis. In 2018 IEEE 20th International Conference on High Performance Computing and Communications; IEEE 16th International Conference on Smart City; IEEE 4th International Conference on Data Science and Systems (HPCC/ SmartCity/ DSS), Exeter, United Kingdom, 2018: 313-320. [DOI:10.1109/HPCC/SmartCity/DSS.2018.00072]

18. Lu K, Yu S, Yu M, Sun D, Xing H, An J, et al. Scientometric Analysis of SIRT6 Studies. Medical science monitor: international medical journal of experimental and clinical research(IJCEM), 2018; 24:8357-71. [DOI:10.12659/MSM.913644] [PMID] [PMCID]

19. Lu K, Yu S, Yu M, Sun D, Huang Z, Xing H, et al. Bibliometric analysis of tumor immunotherapy studies. Medical science monitor: international medical journal of experimental and clinical research(IJCEM), 2018; 24:3405-14. [DOI:10.12659/MSM.910724] [PMID] [PMCID]

20. Liao CS, Ho YS, Hsu YHE. Bibliometric analysis of human papillomavirus research in period of 1991 to 2005. Paper presented in Taipei Medical University's 94th Annual Teacher and Student Joint Academic Research Conference. Taipei, Taiwan. 2006. Poster Presentation.

21. Yousefi A, Gilvari A, Shahmirzadi T. Quantitative and Qualitative Review of Web of Science ISI Articles by Iranian Authors in Microbiology. Iranian Journal of Medical Microbiology(Iran J Med Microbiol), 2012; 6(3):59-75

22. Baji F, Azadeh F, Parsaei-Mohammadi P, Parmah S. Mapping Intellectual Structure of Health Literacy Area Based on Co-Word Analysis in Web of Science Database during the Years 1993-2017. Isfahan University of Medical Sciences, Journal of Health Information 
Management (Health Inf Manag), 2018; 15(3):139-45. [In Persian]

23. Khasseh A, Fakhar M, Soosaraei M, Sadeghi S. Evaluation of scientific performance of Iranian researchers in parasitology domain in ISI databases. Iranian Journal of Medical Microbiology(Iran J Med Microbiol), 2011; 4(4):41-50. [In Persian]

24. Khasseh AA, Soosaraei M, Fakhar M. Cluster Analysis and Mapping of Iranian Researchers in the Field of Parasitology: With an Emphasis on the Co-authorship Indicators and H Index. Iran J Med Microbiol 2016; 10(2):63-74. [In Persian]

25. Khasseh AA, Fakhar M, Soosaraei M, Sadeghi S. Present situation of scientific productions of Iranian researchers in parasitology domain in ISI databases. Parasitology 2011; 5 (1-2): 53-65. [In Persian]

26. Hosseininasab SH, Makkizadeh F, Zalzadeh A, Hazeri A. The Thematic Structure of Papers on Depression Treatment in PubMed from 2005 to 2014. Isfahan University of Medical Sciences, Journal of Health Information Management (Health Inf Manag), 2016; 13(5):347-53. [In Persian]

27. Makkizadeh F, Hazeri A, Hosininasab S, Soheili F. Thematic Analysis and Scientific Mapping of Papers related to Depression Therapy in PubMed. Iran University of Medical Science, Journal of Health Administration(JHA), 2016; 19(65):51-63. [In Persian]

28. Soheili F, Hasanzadeh P, Mousavi-Chelak A, Khasseh AA. Scientific Mapping of Chronic Heart Failure based on Co- citation Analysis. Health Information Management(Health Inf Manage), 2018; 15(5):226-32. [In Persian]

29. Shahrabi FH, Eskrootchi R, Mohaghegh N, Hosseini AF. A Study of Scientific Collaboration in Iranian Cardiovascular Articles in Web of Science 2002- 2011. Iran University of Medical Science, Journal of Health Administration(JHA), 2014; 17(56):46-55.[In Persian]

30. Hazeri A, Goruhi M. The Intellectual Structure of Knowledge in the Field of Medical Knowledge Management: A Co-Word Analysis. Health Information Management(Health Inf Manage), 2019; 16(3):136-42. [In Persian]

31. Shargh A, Mohammad Hassanzadeh H, Johari K, Valinejadi A, Molaei A, Amanollahi A, et al. The study of the presence of Iranian neuroscience in ISI database based on scientometric factors. Iran University of Medical Science, Journal of Health Administration, 2011; 14(44):61-70.[In Persian]

32. Mostafavi I, Osareh F, Tavakolizadeh-Ravari M. Identifying content structure of «Knowledge and Information Science (KIS)» studies based on co-word analysis of articles in «Web of Science (WoS)» database (2009-2013). Iranian Research Institute for Information
Science and Technology (IRANDOC), 2017; 33(3):1285314. [In Persian].

33. Ahmadi H, Osareh F. Co-word Analysis Concept, Definition and Application. National Studies on Librarianship and Information Organization() (NASTINFO), 2017; 28(1):125-45. [In Persian]

34. Soheili F, Danesh F, Mesrinejad F \& Isfandyari Moghadam A. Lotka's Law of Scientific Productivity and Bradford's Law of Scatter among Researchers at Isfahan University of Medical Sciences based on Web of Science Database. Health Information Management(Health Inf Manage), 2012; 8(6):766-73.[In Persian]

35. Ke W., Yunjiang X., Xiao L., Weichan L. (2013) Analysis on Current Research of Supernetwork through Knowledge Mapping Method. In: Wang M. (eds) Knowledge Science, Engineering and Management. KSEM 2013. Lecture Notes in Computer Science, vol 8041. Springer, Berlin, Heidelberg. [DOI:10.1007/978-3642-39787-5_45]

36. Melcer E, Nguyen THD, Chen Z, Canossa A, El-Nasr MS, Isbister K. Games research today: Analyzing the academic landscape 2000-2014. The 10th International Conference on the Foundations of Digital Games. Pacific Grove, USA; June 22-25; 2015.

37. Liu GY, Hu JM, Wang HL. A co-word analysis of digital library field in China. Scientometrics, 2012; 91(1):203217. [DOI:10.1007/s11192-011-0586-4]

38. Law J, Bauin S, Courtial J, Whittaker J. Policy and the mapping of scientific change: A co-word analysis of research into environmental acidification. Scientometrics, 1988; 14(3-4):251-64. [DOI:10.1007/BF02020078]

39. Raeeszadeh M, Karamali M. Scientific mapping of military trauma papers using co-word analysis in Medline. Journal of Military Medicine, 2018; 20(5):476-87.[In Persian]

40. Soheili F, Khasseh A, Koranian P. Thematic trends of concepts in Knowledge and Information Science based on co-word analysis in Iran. National Studies on Librarianship and Information Organization (NASTINFO), 2018; 29(2):171-90. [In Persian]

41. Soheili F, Khasseh AA, Koranian P. Mapping Intellectual Structure of Knowledge and Information Science in Iran based on Co- word Analysis. Journal of Information Processing and Management, 2019; 34(4):1905-38. ]In Persian[

42. Soheili F, Shabani A, Khasseh A. Intellectual Structure of Knowledge in Information Behavior: A Co-Word Analysis. Human Information Interaction, 2018; 2(4):2136. [In Persian] 